resources/publications/influenza/WHO_CDS_CSR_GIP 2005_5/en/, accessed 15 September 2006.

6. Commonwealth of Australia. Australian health management plan for pandemic influenza. 2006. Available at: www.health. gov.au/internet/wcms/publishing.nsf/Content/ohp-pandemicahmppi.htm, accessed 15 September 2006.

7. Commonwealth of Australia. Australian management plan for pandemic influenza. 2005.
8. NSW Health. NSW Health interim influenza pandemic action plan. 2005. Available at: www.health.nsw.gov.au/pubs/2005/ pdf/pandemic_ap.pdf, accessed 15 September 2006.

9. Commonwealth of Australia. National action plan for human influenza pandemic. 2006. Available at: www.dpmc.gov.au/ publications/pandemic/index.htm, accessed 15 September 2006.

10. NSW Government. New South Wales interim human influenza pandemic plan. Available at: www.health.nsw. gov.au/pandemic/docs/nswplan.pdf, accessed 15 September 2006. 곻

\title{
PANDEMIC PLANNING AT THE COAL FACE: RESPONSIBILITIES OF THE PUBLIC HEALTH UNIT
}

\author{
Keith Eastwood, Peter Massey and David Durrheim \\ Hunter New England Population Health \\ Hunter New England Area Health Service
}

\section{ABSTRACT}

Responding to an infectious disease pandemic requires a coordinated approach from all essential services. Public health units across NSW will play an important role in a range of control activities. These include: surveillance, education, communication, case ascertainment, case management (excluding clinical management), infection control, contact tracing, monitoring contacts in home quarantine, surveillance at borders, epidemiological studies and immunisation. Public health units are currently planning for such an emergency and these plans will need to be tested and refined under simulated conditions.
\end{abstract}

A well functioning disease surveillance system is necessary to ensure that the first cases of pandemic influenza are rapidly identified. Following this, control strategies will be implemented to retard the transmission of the virus while a vaccine is being developed. Surveillance will also detect the last case, signifying an end to the crisis. In between these two watershed surveillance events, public health units will play a pivotal role in responding to a pandemic. The purpose of this paper is to describe this role.

\section{INTERNATIONAL, AUSTRALIAN AND NSW PLANS FOR A PANDEMIC}

The World Health Organization has vigorously advocated global readiness for an influenza pandemic and planning by individual nations. ${ }^{1}$ The Australian Government has adopted an inclusive process of policy-making with states and territories. Some of the strategies and plans developed by the Australian Government Department of Health and Ageing are described in the contribution by the Chief Medical Officer in this issue of the Bulletin.

For emergencies occurring in NSW, coordination of the response is governed by the State Emergency and Rescue
Management Act, with the NSW Department of Health legislated to serve as the lead agency in responding to infectious disease emergencies. As all of society will be affected by a pandemic, the NSW Premier's Department is overseeing the involvement of other government departments and agencies in NSW.

Area health services across NSW will play a front-line role in providing clinical care in the event of a pandemic and ensuring appropriate local public health and mental health responses. Once the first few cases of pandemic influenza are identified, emergency departments will be placed on heightened alert to identify suspected pandemic cases. Dedicated influenza clinics will be opened when humanto-human spread has occurred within Australia. These clinics will manage all patients with symptoms suggestive of influenza to reduce the risk of infection to patients attending hospital for other reasons. Fever hospitals and staging facilities are planned for the clinical management of cases when existing acute care facilities are likely to be overwhelmed.

Since 2003, the World Health Organization has been monitoring the status of the avian influenza H5N1 strain that has caused deaths in people who have been in close contact with infected poultry. ${ }^{2}$ It is fair to say that this concern has accelerated global pandemic preparedness.

\section{THE ROLE OF THE PUBLIC HEALTH UNIT}

Public health units will have a number of vital roles during a pandemic, including: surveillance, education, communication, case ascertainment, case management (but not clinical management), infection control, contact tracing, monitoring contacts in home quarantine, surveillance at borders, epidemiological studies and immunisation. While these duties are not foreign to public health units, the potential number of cases and urgency of response, and the need to maintain large databases, makes pandemic influenza a particular challenge. The full scope of implementation of certain of these activities is yet to be determined and the responsibility for delivery may be shared with other 
TABLE 1

\section{STAGES AND PHASES OF A PANDEMIC, AND THE AIM OF THE AUSTRALIAN GOVERNMENT RESPONSE}

$\begin{array}{lll}\text { Pandemic stages } & \text { Phases of the pandemic } & \text { Aim of Australian Government response } \\ \begin{array}{l}\text { Pandemic influenza } \\ \text { containment stage }\end{array} & \begin{array}{l}\text { Localised human to human spread: } \\ \text { Australian phases } 3,4,5 \& 6 \mathrm{a}\end{array} & \begin{array}{l}\text { To aggressively contain and eliminate the disease. If this is } \\ \text { unachievable, the secondary aim is to retard transmission and } \\ \text { provide additional time for vaccine development }\end{array} \\ \begin{array}{l}\text { Pandemic influenza post- } \\ \text { containment stage }\end{array} & \begin{array}{l}\text { Widespread transmission in the } \\ \text { general population: }\end{array} & \begin{array}{l}\text { To maintain health services and other core services within the } \\ \text { limitations of remaining resources }\end{array} \\ & \text { Australian phase } 6 \mathrm{~b}\end{array}$

agencies. Public health unit planning must continue to interrelate with broader area health service planning. ${ }^{3}$

The Australian Government Department of Health and Ageing has implemented a phased approach to responding to a pandemic threat that corresponds to the epidemiological situation of novel influenza strains. The activity of public health units is governed by these designated phases ${ }^{4}$, while the specific response obligations are described in the NSW Health Interim Influenza Pandemic Action Plan ${ }^{5}$ and the Pandemic Influenza Response Protocol contained in the NSW Notifiable Diseases Manual. At the time of writing we are in Australian phase 0 and Overseas phase 3.

The Australian government response to a pandemic is divided into two broad stages according to local epidemic progression: containment and post-containment. The aim of these two stages, and how they relate to the pandemic phases, is provided in Table 1. The activities and plans of public health units vary during these two different stages as described in the rest of this article.

\section{DIAGNOSIS, SURVEILLANCE AND NOTIFICATION OF CASES OF PANDEMIC INFLUENZA}

\section{Containment stage}

During the containment stage of a pandemic, public health units will notify the NSW Communicable Diseases Branch of any human cases meeting the current case definition for suspected avian or pandemic influenza. When influenza clinics have been activated, public health units will work with clinical services to ensure accurate collection of data related to suspected cases, contacts and deaths for epidemiological and statistical purposes.

To achieve prompt recognition of the introduction into NSW of a pandemic influenza strain, public health units are reliant on notification by clinicians of cases of disease that are compatible both clinically and epidemiologically with the prevailing case definition. As this definition changes, the updated definition will be available at www.health.nsw. gov.au/pandemic/.

All patients that meet the case definition should have respiratory viral culture swabs collected for laboratory testing. Specimen quality is important for successful diagnosis. Testing for influenza by reverse transcriptase polymerase chain reaction (PCR) permits confirmation of the influenza subtype within 24 hours of receipt of a suitable specimen. This test is currently offered at a limited number of reference laboratories and is only available on an urgent basis after consultation with a clinical microbiologist.

All pathology requests for the $\mathrm{H} 5 \mathrm{~N} 1$ or pandemic strain should be notified to the local public health unit by the receiving laboratory or requesting doctor (prior to referral of the specimen to the reference laboratory) so that prompt investigation, including contact tracing, can be initiated. An effective surveillance system is reliant on fostering and maintaining a strong collaborative network with GPs, emergency departments, laboratories and respiratory physicians. Influenza viruses can also be cultured and subtyped, although the timeframe required precludes this as a practical surveillance or initial diagnostic tool. Samples that are negative for the pandemic strain should be tested for seasonal influenza and other respiratory pathogens. The laboratory can recommend other samples or testing strategies to the referring doctor or public health unit. Once the pandemic strain has become established in Australia or a region of this country, the need for urgent laboratory diagnosis may not be necessary or practical on a large-scale basis. The case definition used for surveillance, notification and treatment will reflect the changing model of control.

\section{Post-containment stage}

During the post-containment stage public health units may only be required to provide tallies of new cases and deaths.

\section{CASE MANAGEMENT, CONTACT TRACING AND HOME QUARANTINE}

\section{Containment stage}

During the containment stage the public health unit's role will be to work with clinicians to facilitate the urgent investigation of suspected cases that accord with the case definition. They will ensure:

- appropriate specimen collection

- rapid laboratory testing

- appropriate management of cases to reduce infectiousness

- contact tracing

- provision of information to cases and contacts

- provision of prophylaxis to contacts

- infection control advice to cases, contacts and health care workers 
- coordination of the management of cases and contacts in home isolation or quarantine for the residual of the incubation period determined by the Australian Government.

\section{Post-containment stage}

During the post-containment stage the contact tracing measures listed above will not generally be required because of the ubiquitous nature of infection and overwhelming workload; however, they may be effective in protecting isolated communities.

The public health units across NSW will be testing case management and contact tracing protocols through field exercises such as the Cumpston national exercise carried out in October 2006 and the Paton exercise in NSW to be carried out in November 2006.

\section{IMMUNISATION}

The development and delivery of an effective vaccine will be vital for limiting the impact of a pandemic although it is not anticipated that one will be available until late in the containment stage or, more likely, the post-containment stage. The logistics of immunising large numbers of people from varying socioeconomic and cultural backgrounds across a broad geographical area, whilst managing issues such as security and prioritisation of supply, must be determined beforehand and tested under simulated conditions. ${ }^{6}$ Currently the mass vaccination plan has not been developed; however, the public health units' role will be to manage the logistics of vaccine supply and mass vaccination clinics in a timely, efficient and orderly fashion. Increasing the number of staff who are able to immunise, and developing and testing mass vaccination plans, are imperative to the success of the community vaccination program.

In addition, public health units will continue to encourage uptake of the pneumococcal vaccine to reduce the risk of concomitant bacterial infection. Vaccination against seasonal influenza is always recommended for people in 'at risk' groups but is particularly important during a pandemic alert period as it reduces the possibility of misdiagnosis with the pandemic strain and the potential for hybridisation.

\section{SURVEILLANCE AT BORDERS}

The Commonwealth Quarantine Act (1908) requires international ships and aircraft to report all suspected cases of influenza-like illness amongst passengers or crew to the Australian Quarantine Inspection Service before landing or berthing as part of routine pratique. This information is communicated through the Director of the Communicable Diseases Branch - in the Director's capacity as NSW Chief Human Quarantine Officer - to the local public health unit for management of cases and contacts. This system should be equally functional during a pandemic, although the captain of an international ship or aircraft will be expected to actively report the health status of their passengers.
Once human-to-human spread of a novel influenza strain has been confirmed and Overseas Phase 4 has been declared, area health services that contain an international air or sea port may be requested to participate in active surveillance of incoming (and possibly outgoing) passengers for influenza signs and symptoms. Thus collaborative planning with the Australian Quarantine Inspection Service and port authorities is necessary during the pandemic alert phase. During the containment stage the public health unit will be responsible for case assessment and appropriate infection control. In addition, where a person meets the case definition, there will need to be active follow up of all fellow passengers and crew that meet the Australian Government definition of a contact that is current at that point in time.

\section{SURGE CAPACITY AND WORKLOAD PRIORITISATION}

A dramatically increased workload with potentially decreased staff numbers (due to sickness or family commitments) should be anticipated during a pandemic. All area health services, including the public health units, are expected to develop business continuity plans, and these plans will need to include a workforce plan that addresses the need to supplement staffing during a pandemic. Alternative practices such as working from home where feasible may assist whilst also reducing exposure risks. In addition, prior consideration should be given to identifying essential tasks that must be continued within the emergency.

\section{EDUCATION AND COMMUNICATION}

It is impossible to predict the degree of personal anxiety and social disruption during a pandemic event, but maintaining proactive communication will help. ${ }^{7}$ Early preparation should include using diverse media outlets and forums to disseminate fact sheets and infection control advice to the public and health workers so that a relationship of trust is established prior to the pandemic. ${ }^{8}$ To facilitate dissemination and receipt of information, public health units should establish communication systems including contact lists, contracts with telecommunication suppliers, menu driven telephone services, 1800 numbers, websites, fact sheets and fax alerts.

The public education message is primarily the responsibility of the Australian Government as this ensures uniformity of advice. These messages may need to be tailored at a state or local level, for instance by providing area-specific telephone numbers and the addresses of influenza clinics and other facilities. The public health unit will play a role in ensuring adequate local coverage has occurred.

\section{PANDEMIC INFLUENZA IN RURAL COMMUNITIES}

Population density is an important determinant of the spread of communicable diseases, hence influenza attack rates in rural communities, are expected to be lower than 
in urban settings. However, attack rates may be very high in specific communities, with a profound effect on medical and essential service infrastructure should key personnel be affected. Pandemic preparation and planning places a considerable additional burden on available health staff. ${ }^{9}$ This is challenging in relatively well resourced metropolitan areas but even more demanding in country towns with fewer staff.

Planning to mitigate the impact of pandemic influenza in rural areas must address the issue of transporting people, personal protective equipment, antiviral therapy and vaccines over large distances within a short timeframe. This may require the adoption of innovative courier networks, including local transport companies, service agencies and volunteer groups.

Many rural areas have greater levels of socio-economic disadvantage and higher proportions of Aboriginal and Torres Strait Islander people. These communities may struggle during a pandemic, and planning should therefore ensure that their particular needs are considered.

\section{DISCUSSION}

Even with mathematical modeling and the lessons of history, it is impossible to predict the full impact of an influenza pandemic. Strategic planning should anticipate a profound disruption to social and health infrastructure. Currently, the focus of world attention is on a relatively small number of human cases of infection with the avian influenza H5N1 subtype, but the next pandemic strain may demonstrate distinctly different clinical and epidemiological features. Public health planning and preparation should be suitably adaptable to respond to evolving disease characteristics and challenging logistical situations. Indeed, the measure of a successful plan is its capacity to adapt to a range of serious infectious and environmental emergencies. This can only be achieved by meticulous planning and the practical experience gained through simulated exercises. Although a number of exercises have been organised and enacted at a local, state and national level, further exercises are necessary to practically test potentially fragile links in the response chain.

\section{ACKNOWLEDGEMENTS}

The authors gratefully acknowledge the input from Dominic Dwyer, Mark Ferson and the Hunter New England Population Health Pandemic Influenza Taskgroup.

\section{REFERENCES}

1. World Health Organization. WHO pandemic influenza draft protocol for rapid response and containment. Geneva: WHO, 2006. Available at: www.who.int/csr/disease/avian_influenza/ guidelines/draftprotocol/en/index.html, accessed 17 October 2006.

2. World Health Organization. Confirmed human cases of Avian Influenza A(H5N1). Available at: www.who.int/csr/disease/ avian_influenza/country/en/, accessed 17 October 2006.

3. NSW Health. Checklist for area health service plans for an influenza pandemic. Available at: www.health.nsw.gov. au/infect/pdf/checklist_plans.pdf, accessed 17 October 2006.

4. Commonwealth Department of Health and Ageing. Australian health management plan for pandemic influenza. May 2006. Available at: www.health.gov.au/internet/wcms/Publishing. nsf/Content/ohp-pandemic-ahmppi.htm, accessed 17 October 2006.

5. NSW Health. NSW Health interim influenza pandemic action plan. November 2005. Available at: www.health.nsw.gov.au/ pubs/2005/pdf/pandemic_ap.pdf, accessed 17 October 2006.

6. Daems R, Del Giudice G, Rappuoli R. Anticipating crisis: Towards a pandemic flu vaccination strategy through alignment of public health and industrial policy. Vaccine 2005; 23: 5732-42.

7. World Health Organization. Non pharmaceutical interventions for pandemic influenza, national and community measures. Emerg Infect Dis 2006;12: 988-94.

8. NSW Health. Influenza and communicable diseases communications plan. Version 2.0, October 2005.

9. Harnden A. Dealing with uncertainty: perspective from primary care. Br Med J 2006; 332: 791-2. 용 